\title{
Environmental factors associated with amphibian breeding in streams and springs: effects of habitat and fish occurrence
}

\author{
Raoul Manenti*, Roberta Pennati
}

Abstract. Streams are among the most threatened aquatic habitats for amphibians. Amphibians often demonstrate a complex community structure and investigations are mainly performed on pond-dwelling species, whereas data regarding streamdwelling species is still scarce. The aim of this study was to evaluate the relevance of stream features and the effects of the occurrence of predatory fish on the community structure of amphibians. To assess the occurrence of breeding among amphibians (in Northern Apennine streams), sampling was performed on 57 stream and spring sites between early March and late May 2014. The research process recorded the presence of four breeding species (Salamandra salamandra, Salamandrina perspicillata, Bufo bufo, and Rana italica) and discovered that the community structures of amphibians were significantly connected to different habitat features. The investigation showed that fish presence is the primary habitat feature that affects the communities of amphibians: B. bufo was the only amphibian species not affected by fish presence, while the other species avoided sites with fish. Sun exposure, depth of water and slope inclination played important roles in affecting amphibian breeding. Our study confirms that fish presence in small streams can be detrimental for different amphibian species.

Keywords: breeding, Bufo, palatability, predator, redundancy analysis, Salamandra, trout.

Stream ecology is multidimensional, with the diversity and the presence of species being dependent upon situations and processes that exist at multiple, spatial and temporal levels (Chee and Elith, 2012; Dudley et al., 2015). Flow regime, features of the surrounding landscape and the impact of human activities, in terms of pollution and water trophic resources, are the main factors that shape stream biodiversity (Montana and Winemiller, 2010). The knowledge of habitat use and the structure of communities are key aspects to understanding the factors that determine the distribution and abundance of organisms for conservation purposes (Walther and Whiles, 2008; Ficetola et al., 2011a). Many amphibians breed in streams and several studies document the important ecological role that amphibians play in lotic systems (Gillespie et al., 2004; Cvetkovic et al., 2009; Keitzer and Goforth, 2013). In particular, stream amphibians are comprehensive examples of the "reciprocal subsidies" occurring

Dipartimento di Bioscienze, Università degli Studi di Milano, Via Celoria, 2620133 Milano, Italy

*Corresponding author;

e-mail: raoulmanenti@gmail.com between the stream and its riparian areas (Earl et al., 2014). Stream biota provides fundamental ecological resources to the surrounding areas also in terms of living biomass. In particular, a high biomass richness of stream amphibians means that they may play an important role in stream-riparian dynamics (Gillespie et al., 2004; Cvetkovic et al., 2009). At the same time, landscape composition and features can strongly affect the distribution of amphibians (Hartel et al., 2010; Gustafson et al., 2011; Manenti et al., 2013).

Streams are among the most threatened breeding habitats for amphibians. Interactions between stream-dwelling amphibians have received less attention than those among ponddwelling species. Communities of amphibians may be quite complex in river catchment basins (Welsh and Hodgson, 2011) and both pollution and human habitat fragmentation may affect them (Kupferberg et al., 2012). One of the main factors discriminating lotic and lentic habitats is the availability of food: stream amphibian larvae often have little zooplankton or phytoplankton for feeding (Gillespie et al., 2004). Moreover, it has been suggested that the struc- 
ture of stream communities may be strongly related to the presence of fish such as salmonids, which are potential predators of tadpoles and salamander larvae and potential competitors for macrobenthos prey (Lowe and Bolger, 2002; Gillespie, 2010). In pre-Alpine and Apennine streams, trout presence results from natural dispersal and their introduction for sport fishing (Mazzotti, 1993). In mountain lakes and ponds, introduced salmonids may be a great threat to once fishless freshwater ecosystems (Tiberti and von Hardenberg, 2012). Introduced fish become intensive predators of the benthic community, changing plankton communities and preying on amphibian larvae and tadpoles (Tiberti and von Hardenberg, 2012).

The impact of salmonids on the communities of amphibians within stream habitats has been little investigated. Therefore, the study of amphibians breeding in streams and watercourses, in connection with fish presence, would be particularly important for ecological and conservation purposes, by being able to provide precise management guidelines for fishing, as well as for the preservation of amphibians. The study was focused on the analysis of the community structures of amphibians breeding in the streams and springs of the Northern Apennines (Italy), in order to: 1) evaluate the relative importance of biotic and abiotic features for the community structures of amphibians; 2) compare the variety and composition of the communities of amphibians in streams in connection with fish presence.

The area where the investigation was performed is located in the Northern Apennines, in Liguria (Italy), between the mountains Caucaso, Lavagnola and Becco (lat.: 44.49N, long.: 9.17564E).

From early March to late May 2014, surveys were conducted during both night and daytime, in order to evaluate the presence/absence of breeding adults, eggs or larvae of amphibians in streams and springs within the catchment basins of Lavagna, Lentro and Trebbia. All surveys were performed by the same observer. Each site was surveyed at least once during daytime, and at least once after dusk, using spotlights to illuminate the stream. Surveys included the active examination of shelters, substrates and river banks. Each survey on streams was conducted along a linear transect (50 meters). Springs were surveyed along a maximum length of 15 meters downstream from the resurgence point. The surveys were conducted by sampling 57 different sites, which belong to the 3 main hydrographic networks (Lavagna, Lentro and Trebbia) of the area, including 12 springs, 33 first order streams, 4 sites in a second order stream (Rio Cavagnaro) and 8 sites in the 3 main watercourses. Multiple sampling locations were introduced wherever environmental conditions (e.g. landscape, stream morphology) within the same stream showed significant changes; the average distance between sampling locations within the same stream was $1710 \mathrm{~m}$.

Six different features were chosen and upon which data on habitats was collected: area of the site; maximum water depth; degree of shade; streambed heterogeneity; bank slope; fish presence. Streambed heterogeneity is an indicator of the availability of shelters, depending on the percentage of alternating substrate elements (sand, gravel, stones, sunken branches; see Petersen, 1992). Each spring or stream transect was classified using the following rank scale: 1) absence of diversification, one single substrate element covering almost $100 \%$ of the site; 2) poorly diversified, two substrate elements covering $>90 \%$ of the transect; 3 ) quite diversified, at least three elements present in at least $10 \%$ of the transect; 4) highly diversified, $>90 \%$ of the transect presenting an alternation of at least three elements. Measuring the percentage of aquatic site surface covered by shade allowed assessing different degrees of shade with the following rank scale: 1 ) shade covering $<10 \%$ of the surface; 2 ) shade covering between 10 and $30 \%$ of the surface; 3 ) shade covering $30-50 \%$ of the surface; 4 ) shade covering $60-90 \%$ of the surface; 5 ) shade covering $>90 \%$ of the surface.

Fish presence was assessed relying on the local district's official fish distribution map (Seu and Borroni, 2005) which provides data on the three basins investigated and on most of their tributaries. Moreover, two surveys based on visual assessment were performed both during night and daytime in each site. Where the fish distribution map stated their presence, fish were considered as present even in those sites where no fish $(n=3)$ were recorded.

In order to assess the probability of recording each species of amphibians during each survey, and in order to calculate the probability of failing to record species that were present (i.e., false absence), Presence 5.5 software (Hines, 2006) has been used. In order to evaluate the relative role of environmental factors on the multivariate community structure (i.e. species composition) of amphibians, the study involved a constrained redundancy analysis (RDA), using the vegan package (Oksanen et al., 2005). Therefore, this analysis considered only the species occurring in more than $15 \%$ of surveyed sites. As the cases of failing to record species were very low $(<0.04 \%)$, data was recorded for each site on the presence/absence of each species. Significance of the explained variance was calculated performing ANOVAlike permutation tests (10 000 permutations) (Borcard et al., 2011).

Moreover, in order to connect the presence of each amphibian species with the recorded habitat features in each stream, generalized linear mixed models (GLMMs) were 
used assuming binomial error distribution. Furthermore, in order to take into account only those streams belonging to the same basin and to the same hydrographic network, the three catchment basins and the first stream located downstream of each site were included as random factors. The study involved the elaboration of models representing all possible additional combinations of independent variables and included compared models based on AICc values (Rolls, 2011). Variance inflation factor (VIF) was calculated within each model and only models with a VIF value $<5$ were considered. The significance of the variables that were used within the best model was assessed using a Wald $\chi^{2}$ test. Glmer, dredge and Anova functions were used in the nlme, MuMIn and car packages. All statistical analyses were performed in the R 3.2 environment.

Within the 57 investigated sites, six amphibian species were recorded: the fire salamander Salamandra salamandra (occurrence, $\mathrm{O}=$ 46\%); the spectacled salamander Salamandrina perspicillata $(\mathrm{O}=16 \%)$; the Italian stream frog Rana italica $(\mathrm{O}=25 \%)$; the common toad Bufo bufo $(\mathrm{O}=19 \%)$; the common frog $R$. temporaria $(\mathrm{O}=3.5 \%)$; the alpine newt Mesotriton alpestris apuanus $(\mathrm{O}=1.7 \%)$. Detectability of these species was generally high ( $>0.9)$ and for the four species which showed occurrence values $>15 \%$, the failure to detect species was $<0.04 \%$.

The relationship between communities of amphibians and habitat features explained 35\% of the variations and it was considered as highly significant (permutation test: $P \leqslant 0.001$ ). The first RDA axis was represented by fish presence, while the second was the highly accessible sites with high substrate heterogeneity. The only species that showed a positive relation to fish presence was B. bufo, while the other species avoided sites with fish (fig. 1). Within the GLMMs analysis of the single species, fish presence was included in the best models as an explanation of the presence of three amphibian species: it had a negative connection with
Figure 1. Results of constrained redundancy analysis showing the relation between habitat features and the distribution of amphibian species. Ss, Salamandra salamandra; $\mathrm{Sp}$, salamandrina perspicillata; Bb, Bufo bufo; Ri, Rana italica. Constraining variables are represented by grey arrows. This figure is published in colour in the online version. 
Table 1. Results of GLMMs analysis showing the variables included in the best model selected on the basis of AIC weigh, which explains the distribution of each species.

\begin{tabular}{|c|c|c|c|c|c|}
\hline Species & Variables in the best model & $B$ & $S E$ & $X^{2}$ & $P$ \\
\hline \multirow[t]{2}{*}{ Salamandra salamandra } & Shadow & 6.16 & 2.96 & 4.32 & 0.03 \\
\hline & Fish occurrence & -4.23 & 1.57 & 7.26 & $<0.01$ \\
\hline \multirow[t]{2}{*}{ Salamandrina perspicillata } & Area & -5.07 & 4.4 & 4.36 & 0.03 \\
\hline & Shadow & -13.56 & 5.7 & 5.53 & 0.01 \\
\hline \multirow[t]{3}{*}{ Bufo bufo } & Fish occurrence & 23.54 & 7.56 & 12.01 & $<0.001$ \\
\hline & Shadow & -10.15 & 4.04 & 11.25 & $<0.001$ \\
\hline & Slope & -4.34 & 1.31 & 10.39 & $<0.001$ \\
\hline \multirow[t]{3}{*}{ Rana italica } & Slope & -23.38 & 9.81 & 5.65 & 0.01 \\
\hline & Depth & 22.09 & 8.83 & 6.73 & $<0.01$ \\
\hline & Fish occurrence & -16.75 & 8.30 & 4.00 & 0.04 \\
\hline
\end{tabular}

S. salamandra and $R$. italica, while it was positively related to $B$. bufo (table 1 ).

The four most common species were related to particular combinations of habitat factors: the fire salamander seemed to prefer shady sites without fish; the Italian stream frog was more frequent in deep accessible sites, without fish; the common toad occurred in sunny sites with fish and low river slopes; $S$. perspicillata seemed to breed more frequently in small and sunny streams or spring pools (table 1).

Our results showed that fish presence is the main habitat feature that affects the breeding of amphibians, at least among those species that occurred in $>15 \%$ of the sites among the surveyed Apennine streams. Fish predation is often considered as a major factor driving amphibian breeding success (Van Buskirk, 2003; Denoël et al., 2005). In stream habitats, fish are considered as indicators of good microhabitat features, potentially suitable also for amphibians (Manenti and Bianchi, 2014). However, fish are predators of amphibian larvae and macrobenthos, thus affecting amphibian survival by consumptive and non-consumptive processes (Tiberti and von Hardenberg, 2012). Thus, although not specifically assessed, fire salamander larvae are likely to suffer such predatory activity. Moreover, it is known that $S$. salamandra breeding prevails in sites with high macrobenthos abundance (Manenti et al., 2009) and, therefore, may compete with fish for this resource.
On the contrary, B. bufo breeds in pools where fish are present. Such a positive relation between fish and $B$. bufo tadpoles is the most surprising finding of the study. B. bufo tadpoles are well known not to be palatable to fish (Ficetola et al., 2011b), and the species could be favored by trout presence, since competition with other amphibians can therefore be reduced. The co-occurrence of bufonid tadpoles and fish has already been recorded, especially in the neartic areas (Bull and Marx, 2002; Knapp, 2005; Welsh et al., 2006). The use of chemical repellents is one of the strategies used by amphibians against predators (Knapp, 2005) and it is more effective towards fish and other vertebrates than towards invertebrates (Gunzburger and Travis, 2005). Univariate analyses also showed that $R$. italica had a negative relation to fish presence, although this species is often observed in streams with fish (Romano et al., 2012). Preliminary data (Manenti et al., unpublished) showed that the species occurs in streams with fish mainly in co-occurrence with $B$. bufo, therefore allowing the consideration that there might be a possible role played by $B$. bufo tadpoles in reducing $R$. italica predation by fish.

Generally, amphibian larvae could be differentiated between those living in ephemeral sites without fish, those living in permanent habitats that are palatable to fish, and those living in permanent habitats that are unpalatable to fish (Welsh et al., 2006). Our study shows that the 
B. bufo may be considered the only representative of the third group in the Apennine streams, while all other species might be representative of the second group. These species probably have been facing only recently the predation pressure of fish, possibly as a result of the introduction of salmonids by humans.

Streams are especially important to amphibians in our investigation area, because the valley slopes and structures allow the existence of very rare locations with ponds and sitting waters. Therefore, the ecological context of this area is particularly favorable for investigating the role of lotic habitat features on the distribution of amphibian species, as well as evaluating the human impact of fish introduction. Our study confirms that fish presence in small streams can be detrimental for different amphibian species, and that fish-free sites should be attentively preserved.

Acknowledgements. We thank B. Hossack, two anonymous reviewers and R. Iannelli for their precious suggestions.

\section{References}

Borcard, D., Gillet, F., Legendre, P. (2011): Numerical Ecology With R. Springer, New York.

Bull, E.L., Marx, D.B. (2002): Influence of fish and habitat on amphibian communities in high elevation lakes in northeastern Oregon. Northwest Sci. 76: 240-248.

Chee, Y.E., Elith, J. (2012): Spatial data for modelling and management of freshwater ecosystems. Int. J. Geogr. Inf. Sci. 26: $2123-2140$.

Cvetkovic, D., Tomasevic, N., Ficetola, G.F., CrnobrnjaIsailovic, J., Miaud, C. (2009): Bergmann's rule in amphibians: combining demographic and ecological parameters to explain body size variation among populations in the common toad Bufo bufo. J. Zoolog. Syst. Evol. Res. 47: 171-180.

Denoël, M., Dzukic, G., Kalezic, M.L. (2005): Effects of widespread fish introductions on paedomorphic newts in Europe. Conserv. Biol. 19: 162-170.

Dudley, M.P., Ho, M.C., Richardson, C.J. (2015): Riparian habitat dissimilarities in restored and reference streams are associated with differences in turtle communities in the southeastern Piedmont. Wetlands 35: 147-157.

Earl, J.E., Castello, P.O., Cohagen, K.E., Semlitsch, R.D. (2014): Effects of subsidy quality on reciprocal subsidies: how leaf litter species changes frog biomass export. Oecologia 175: 209-218.
Ficetola, G.F., Marziali, L., Rossaro, B., De Bernardi, F., Padoa-Schioppa, E. (2011a): Landscape-stream interactions and habitat conservation for amphibians. Ecol. Appl. 21: 1272-1282.

Ficetola, G.F., Siesa, M.E., Manenti, R., Bottoni, L., De Bernardi, F., Padoa-Schioppa, E. (2011b): Early assessment of the impact of alien species: differential consequences of an invasive crayfish on adult and larval amphibians. Div. Distrib. 17: 1141-1151.

Gillespie, G. (2010): Population age structure of the spotted tree frog (Litoria spenceri): insights into population declines. Wildlife Res. 37: 19-26.

Gillespie, G.R., Lockie, D., Scroggie, M.P., Iskandar, D.T. (2004): Habitat use by stream-breeding frogs in southeast Sulawesi, with some preliminary observations on community organization. J. Trop. Ecol. 20: 439-448.

Gunzburger, M.S., Travis, J. (2005): Critical literature review of the evidence for unpalatability of amphibian eggs and larvae. Journal of Herpetology 39: 547-571.

Gustafson, D.H., Malmgren, J.C., Mikusinski, G. (2011): Terrestrial habitat predicts use of aquatic habitat for breeding purposes - a study on the great crested newt (Triturus cristatus). Ann. Zool. Fennici. 48: 295-307.

Hartel, T., Schweiger, O., Ollerer, K., Cogalniceanu, D., Arntzen, J.W. (2010): Amphibian distribution in a traditionally managed rural landscape of eastern Europe: probing the effect of landscape composition. Biol. Conserv. 143: 1118-1124.

Hines, J.E. (2006): PRESENCE2 - software to estimate patch occupancy and related parameters. USGS-PWRC. Available at http://www.mbr-pwrc.usgs.gov/software/ presence.html.

Keitzer, S.C., Goforth, R.R. (2013): Salamander diversity alters stream macroinvertebrate community structure. Freshwater Biol. 58: 2114-2125.

Knapp, R.A. (2005): Distribution patterns of lentic-breeding amphibians in relation to ultraviolet radiation exposure in western North America. Biol. Conserv. 121: 265-279.

Koperski, P. (2011): Diversity of freshwater macrobenthos and its use in biological assessment: a critical review of current applications. Environ. Rev. 19: 16-31.

Kupferberg, S.J., Palen, W.J., Lind, A.J., Bobzien, S., Catenazzi, A., Drennan, J., Power, M.E. (2012): Effects of flow regimes altered by dams on survival, population declines, and range-wide losses of California riverbreeding frogs. Conserv. Biol. 26: 513-524.

Lowe, W.H., Bolger, D.T. (2002): Local and landscape-scale predictors of salamander abundance in New Hampshire headwater streams. Conserv. Biol. 16: 183-193.

MacKenzie, D.I. (2006): Modeling the probability of resource use: the effect of, and dealing with, detecting a species imperfectly. J. Wildl. Manag. 70: 367-374.

Manenti, R., Ficetola, G.F., De Bernardi, F. (2009): Water, stream morphology and landscape: complex habitat determinants for the fire salamander Salamandra salamandra. Amphibia-Reptilia 30: 7-15.

Manenti, R., De Bernardi, F., Ficetola, G.F. (2013): Pastures vs forests: do traditional pastoral activities negatively affect biodiversity? The case of amphibians communities. North-Western Journal of Zoology 9: 284-292. 

www.r-project.org (accessed June 2007).

Petersen, R.C. (1992): The RCE - a riparian, channel, and environmental inventory for small streams in the agricultural landscape. Freshwater Biol. 27: 295-306.

Romano, A., Bartolomei, R., Conte, A.L., Fulco, E. (2012): Amphibians in southern Appennine: distribution, ecology and conservation notes in the "Appennino Lucano, Val d'Agri e Lagonegrese" National Park (southern Italy). Acta Herpetol. 7: 203-219.

Seu, A., Borroni, M. (2005): Carta Ittica della Provincia di Genova, Provincia di Genova - Assessorato Caccia e Pesca.

Tiberti, R., von Hardenberg, A. (2012): Impact of introduced fish on common frog (Rana temporaria) close to its altitudinal limit in alpine lakes. Amphibia-Reptilia 33: 303-307.

Van Buskirk, J. (2003): Habitat partitioning in European and North American pond-breeding frogs and toads. Div. Distrib. 9: 399-410.

Walther, D.A., Whiles, M.R. (2008): Macroinvertebrate responses to constructed riffles in the Cache River, Illinois, USA. Environ. Manage. 41: 516-527.

Welsh, H.H., Pope, K.L., Boiano, D. (2006): Sub-alpine amphibian distributions related to species palatability to non-native salmonids in the Klamath mountains of northern California. Div. Distrib. 12: 298-309.

Welsh, H.H., Hodgson, G.R. (2011): Spatial relationships in a dendritic network: the herpetofaunal metacommunity of the Mattole River catchment of northwest California. Ecography 34: 49-66.

Submitted: January 4, 2016. Final revision received: February 2, 2016. Accepted: February 25, 2016.

Associate Editor: Blake Hossack.

Queries to the Authors: In the References list, please put the journal titles in abbreviated form. 